\title{
THE USE OF RADIOSTOLEUM AND CALCIUM SALTS IN RHEUMATISM
}

BY

EDWIN C. WARNER, M.D., B.Sc., M.R.C.P.,*

Assistant Physician, Charing Cross Hospital;

Physician to the Children's Department, Miller General Hospital.

In the absence of the known causes of rheumatic diseases in children, it becomes important that we should study all the factors which may be contributory to it. It is generally realized that rheumatic disease is essentially a disease of the poorer classes of the population, and a study of the diet of such families shows a strikingly low consumption of animal fats--. largely owing to the expensive nature of such foods: this means a correspondingly low consumption of the fat-soluble vitamins $\mathbf{A}$ and $\mathbf{D}$.

There are two indications that a special ration of these fat-soluble vitamins may be a prophylactic measure. In the first place as a result of experimental work on animals ${ }^{1}$, and the results of Mellanby $^{2}$ in cases of puerperal septicæmia, it is generally accepted that vitamin $\mathbf{A}$ is a valuable anti-infective factor. Secondly, in cases of chorea, it has been shown that there is a small fall in the blood calcium and a marked percentage fall in the cerebro-spinal fluid calcium ${ }^{3}$. We know that vitamin $\mathbf{D}$ is essential for the retention and utilization of calcium salts, as has been shown in rickets and infantile tetany, and in osteomalacia and allied bone diseases.

Over a period of three years, at the rheumatism clinic at the Miller Hospital, such ration of extra vitamins has been administered in the form of radiostoleum (B.D.H.), the preparation recommended by Mellanby, in doses of a quarter of a drachm twice daily, made into an emulsion with olive oil $\mathrm{m}$. 15, gum acacia gr. 7, elixir glusidi m. 5 (as recommended by the manufacturers); together with calcium gluconate or calcium lactate in ten grain doses twice daily. In the earlier stages, parathyroid extract (Martindale), was also given by mouth in doses of $\frac{1}{2} \sigma \mathrm{gr}$. twice daily, but as it appeared to make little or no difference to the blood calcium, this was subsequently omitted. Radiostoleum is believed to possess twenty times the vitamin-A, and 100 times the vitamin-D content of cod-liver oil. In most of these cases the children have attended regularly each four or six weeks for a fresh supply, and a record kept of their clinical condition. A few children ceased attending for periods, perhaps on account of moving their homes, or

* Ernest Hart Memorial Scholar, British Medical Association. 
being sent for a period of convalescence, or again due to admission to hospital on account of a rheumatic relapse. Unless the preparations had been taken for at least three months in each twelve months, it was considered that no medicine had been given.

As a control to this special series, all the other rheumatic children have been used. Again they have been classified according to whether they had the particular medicine for a period of at least three months. The usual dose of cod-liver oil and malt and Parrish's food given was 2 drachms of each thrce times daily to a child of ten, with a corresponding reduction to younger children. The children marked as having ' no medicine' either had no medicine at all, or were given a simple coloured syrup mixture which would have no medicinal value, but assured their regular attendance, or else had some preparation for less than three months each year.

If the group given radiostoleum and calcium were benefited, this should show in more than one way. The results are given under three headings:-

(1) The number of definite relapses of acute rheumatism, subacute rheumatism, rheumatic carditis or chorea.

(2) Of the cases showing relapse, the number of cases which showed active carditis. These cases may be such as had an old cardiac lesion which had remained stationary, but which showed evidence of activity in the attack of rheumatic disease; or such as developed carditis for the first time.

(3) The gain in weight of the children.

Each of these groups has to be considered in relation to the average age of the children, an important factor originally emphasized by Wilson, Lingg and Croxford.

On account of the fact that the records were sometimes interrupted for a long period, as by hospital treatment at special centres, it was found best to record the results separately for each year under observation: thus we have recorded the number of children in each group, and also the total number of yearly attendances. It has also been necessary to do this because sometimes the medicine had to be changed as a child got tired of one and had to be changed to another. This occurred least often with the calciumradiostoleum group, and most of the chidren who had radiostoleum had it regularly the whole year through.

The frequency of rheumatic relapses.-These results are briefly recorded in Table 1. From this table it seems quite fair to compare the results with one another as the ages are comparable. It seems that the relapses are fewer in the groups having the calcium and radiostoleum, and there is some benefit by giving malt and cod-liver oil, particularly in subacute rheumatism and chorea. 
TABLE 1.

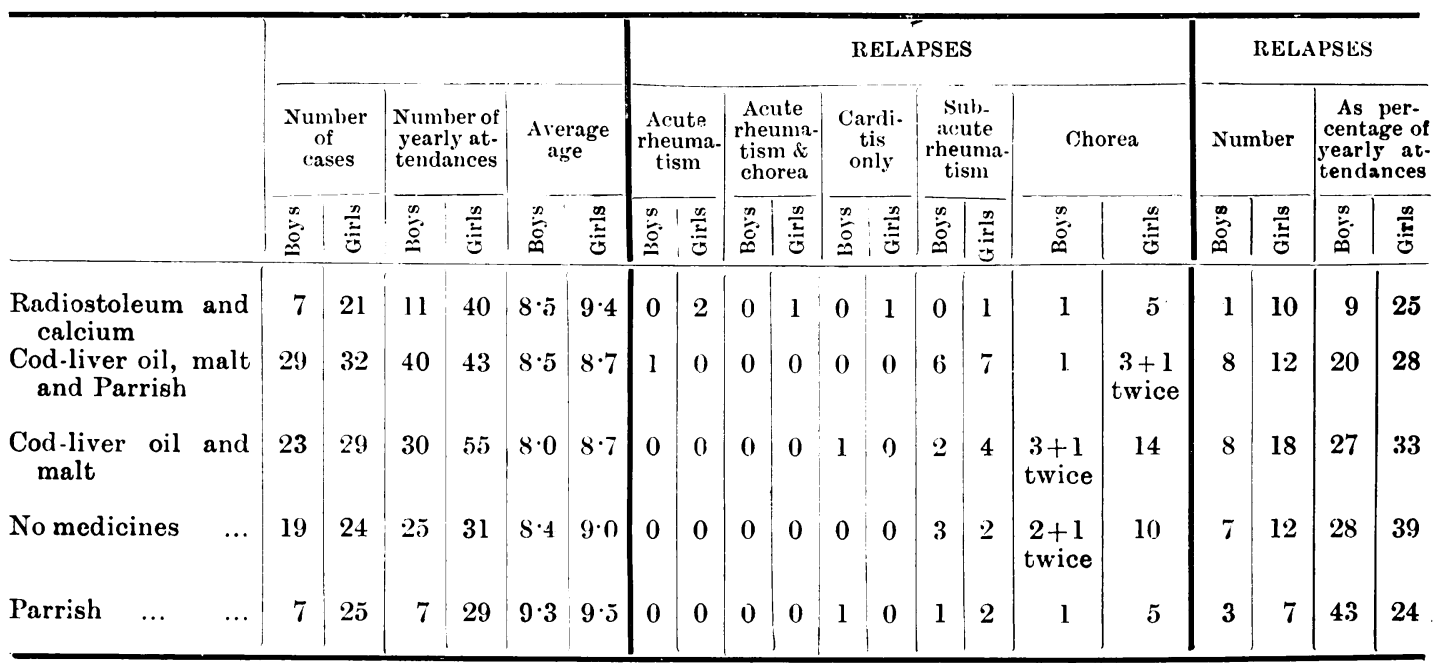

The frequency of carditis in the rheumatic relapses.-The results are shown in Table 2.

TABLE 2.

\begin{tabular}{|c|c|c|c|c|c|c|c|c|c|c|}
\hline & \multirow{2}{*}{\multicolumn{2}{|c|}{$\begin{array}{l}\text { No. of } \\
\text { cases. }\end{array}$}} & \multirow{2}{*}{\multicolumn{2}{|c|}{$\begin{array}{l}\text { No. of yearly } \\
\text { attendances }\end{array}$}} & \multirow{2}{*}{\multicolumn{2}{|c|}{$\begin{array}{l}\text { No. of } \\
\text { relapses }\end{array}$}} & \multicolumn{4}{|c|}{ Active carditis } \\
\hline & & & & & & & $\mathrm{Nu}$ & aber & $\begin{array}{r}\text { As } \\
\text { cents } \\
\text { ye } \\
\text { atten }\end{array}$ & $\begin{array}{l}\text { ger- } \\
\text { ge of } \\
\text { rly } \\
\text { ances }\end{array}$ \\
\hline & Boys & Girls & Boys & Girls & Boys & Girls & Boys & Girls & Boys & Girls \\
\hline $\begin{array}{c}\text { Radiostoleum and } \\
\text { calcium }\end{array}$ & 7 & 21 & 11 & 40 & 1 & 10 & n & 5 & 0 & $12 \cdot 5$ \\
\hline $\begin{array}{l}\text { Cod-liver oil, malt } \\
\text { and Parrish }\end{array}$ & 29 & 32 & 40 & 43 & 8 & 32 & 2 & 3 & 5 & 7 \\
\hline $\begin{array}{r}\text { Cod-liver oil and } \\
\text { malt }\end{array}$ & 23 & 29 & 30 & 55 & 8 & 18 & 3 & 0 & 10 & 0 \\
\hline No medicines & 19 & 24 & 25 & 31 & 7 & 12 & 1 & 3 & 4 & 10 \\
\hline Parrish $\quad \ldots$ & 7 & 25 & 7 & 29 & 3 & 7 & 2 & 1 & 29 & 3 \\
\hline
\end{tabular}

It does not appear that the radiostoleum or any of the other preparations have any value in preventing an attack or relapse of carditis: the results with Parrish's food administered to boys are probably fictitious owing to the small numbers in this group.

The influence of radiostoleum on the gain in weight.-A regular record of the gain in weight of the children is essential in estimating their progress. We are entirely in agreement with Carey Coombs when he said recently that a child who is consistently gaining weight at a fast rate is very unlikely to show a rheumatic relapse. 
TABLE 3.

The gain in Weight Per anNum EXPRessed in pounds and ounces.

\begin{tabular}{|c|c|c|c|c|c|c|c|c|c|}
\hline BOYS. - Age & $5-6$ & $6-7$ & $7-8$ & $8-9$ & $9-10$ & $10-11$ & $11-12$ & & \\
\hline Radiostoleum and calcium... & - & - & $5-\tilde{5}$ & 6-6 & $6-6$ & - & - & & \\
\hline $\begin{array}{c}\text { Cod-liver oil, malt and } \\
\text { Parrish }\end{array}$ & $5-9$ & 4-13 & $7-7$ & 4-11 & $6-3$ & 6-12 & $8-14$ & & \\
\hline Cod-liver oil and malt & $4-13$ & $7-9$ & $5-15$ & $6-12$ & $6-4$ & $6-13$ & - & & \\
\hline No medicines $\quad \ldots \quad \ldots$ & $5-4$ & $5-2$ & $5-6$ & $4-7$ & $11-11$ & $5-10$ & $5-2$ & & \\
\hline GIRLS.-Age & $5-6$ & $6-7$ & $7-8$ & $8-9$ & $9-10$ & $10-11$ & $11-12$ & $12-13$ & $13-14$ \\
\hline Radiostoleum and calcium... & - & $5-11$ & $5-6$ & $9-4$ & $5-3$ & $7-5$ & $8-1$ & $7-11$ & $13-11$ \\
\hline$\underset{\text { Codrish }}{\text { Codiver malt and }}$ & 3-8 & $6-2$ & $6-6$ & $7-0$ & $9-4$ & $9-3$ & $5-8$ & $9-5$ & - \\
\hline Cod-liver oil and malt & $6-0$ & 4-15 & $7-5$ & $7-10$ & $6-8$ & $6-15$ & $9-13$ & $15-9$ & $16-13$ \\
\hline Parrish & $3-14$ & - & $6-0$ & $7-11$ & $6-12$ & $10-2$ & $10-4$ & - & $11-12$ \\
\hline No medicines & 6-3 & $7-3$ & $5-6$ & $5-5$ & $5-7$ & $4-6$ & $13-2$ & - & $11-4$ \\
\hline
\end{tabular}

From this series the children having the preparations of vitamin value have not gained weight any more rapidly than those to whom no medicine had been given.

The influence of radiostoleum on the total blood calcium.-On a series of 15 patients to whom calcium salts and radiostoleum have been administered regularly the whole time, blood calcium estimations have been performed at periods of 3 to 30 months after the administration, and the results compared with the values existing beforehand. The average value before was 10.13 mgms. per cent., and afterwards was $10.01 \mathrm{mgms}$. per cent.

\section{Discussion and Conclusions.}

From this series of cases it appears that an increased ration of vitamins $A$ and $\mathbf{D}$ in the form of regular doses of radiostoleum (equivalent in terms of vitamin $A$ to $1 \frac{1}{4} \mathrm{oz}$. of cod-liver oil, and in terms of vitamin $D$ to $6 \frac{1}{4} \mathrm{oz}$. daily), with calcium, has some action in preventing relapses of chorea and subacute rheumatism; but is of no value in preventing the onset or relapse of carditis; nor has it raised the total blood calcium. It may be that to obtain a more decisive result much larger doses would have to be given, but the dose administered corresponds in this case to a good dose of cod-liver oil.

\section{REFERENCES.}

1. Green, H. N., \& Mellanby, E., Brit. Med. J., Lond., 1928, ii, 691.

2. Mellanby, E., \& Green, H. N., Ibid., 1929, i, 984.

3. Warner, E. C., Lancet, Lond., 1930, i, 339. 